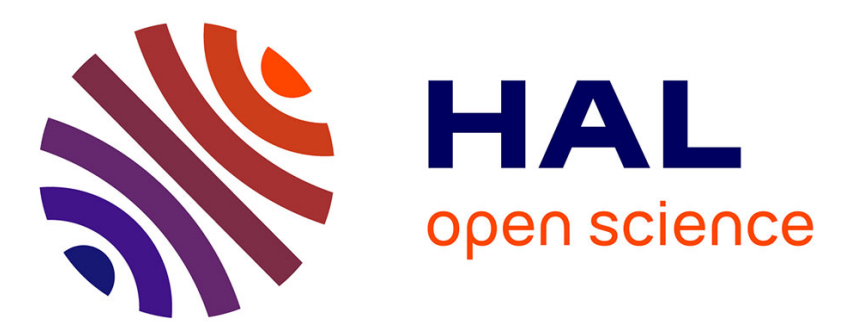

\title{
Shear stress along the conduit wall as a plausible source of tilt at Soufrière Hills volcano, Montserrat
}

\author{
D.N. Green, J. Neuberg, Valérie Cayol
}

\section{To cite this version:}

D.N. Green, J. Neuberg, Valérie Cayol. Shear stress along the conduit wall as a plausible source of tilt at Soufrière Hills volcano, Montserrat. Geophysical Research Letters, 2006, 33, pp.1-5. 10.1029/2006GL025890 . hal-00195332

\section{HAL Id: hal-00195332 \\ https://hal.science/hal-00195332}

Submitted on 11 Oct 2021

HAL is a multi-disciplinary open access archive for the deposit and dissemination of scientific research documents, whether they are published or not. The documents may come from teaching and research institutions in France or abroad, or from public or private research centers.
L'archive ouverte pluridisciplinaire HAL, est destinée au dépôt et à la diffusion de documents scientifiques de niveau recherche, publiés ou non, émanant des établissements d'enseignement et de recherche français ou étrangers, des laboratoires publics ou privés.

$$
\text { Copyright }
$$




\title{
Shear stress along the conduit wall as a plausible source of tilt at Soufrière Hills volcano, Montserrat
}

\author{
D. N. Green, ${ }^{1}$ J. Neuberg, ${ }^{1}$ and V. Cayol $^{2}$ \\ Received 29 January 2006; revised 11 March 2006; accepted 4 April 2006; published 19 May 2006.
}

[1] Surface deformations recorded in close proximity to the active lava dome at Soufrière Hills volcano, Montserrat, can be used to infer stresses within the uppermost $1000 \mathrm{~m}$ of the conduit system. Most deformation source models consider only isotropic pressurisation of the conduit. We show that tilt recorded during rapid magma extrusion in 1997 could have also been generated by shear stresses sustained along the conduit wall; these stresses are a consequence of pressure gradients that develop along the conduit. Numerical modelling, incorporating realistic topography, can reproduce both the morphology and half the amplitude of the measured deformation field using a realistic shear stress amplitude, equivalent to a pressure gradient of $3.5 \times 10^{4} \mathrm{~Pa} \mathrm{~m}^{-1}$ along a $1000 \mathrm{~m}$ long conduit with a $15 \mathrm{~m}$ radius. This shear stress model has advantages over the isotropic pressure models because it does not require either physically unattainable overpressures or source radii larger than $200 \mathrm{~m}$ to explain the same deformation. Citation: Green, D. N., J. Neuberg, and V. Cayol (2006), Shear stress along the conduit wall as a plausible source of tilt at Soufrière Hills volcano, Montserrat, Geophys. Res. Lett., 33, L10306, doi:10.1029/2006GL025890.

\section{Introduction}

[2] Surface deformations recorded at active volcanoes are routinely used to infer pressure conditions within magmatic systems at depth [e.g., Mogi, 1958; Dvorak and Dzurisin, 1997]. The majority of models assume that the deformation is generated by an isotropic pressure source. However, Beauducel et al. [2000] showed that displacements measured at Mount Merapi, Indonesia, are consistent with a deformation field generated by shear stresses at the wall of the shallow conduit (the top $450 \mathrm{~m}$ ). These shear stresses are sustained by the large vertical pressure gradients that develop along the conduit due to viscous flow resistance [e.g., Sparks, 1997].

[3] In this paper we show that shear traction is a plausible source for cyclic deformation recorded close to the active dome at Soufrière Hills volcano (SHV), Montserrat [Voight et al., 1998]. We compare this model to previous isotropic pressurisation models [Voight et al., 1999; Widiwijayanti et al., 2005] and propose that a shear stress deformation source removes the problem of requiring an unrealistically large source radius or overpressure.

\footnotetext{
${ }^{1}$ School of Earth and Environment, University of Leeds, Leeds, UK.

${ }^{2}$ Laboratoire Magmas et Volcans, Université Blaise Pascal, ClermontFerrand, France.
}

Copyright 2006 by the American Geophysical Union. 0094-8276/06/2006GL025890

\section{Tilt Recorded at Soufrière Hills Volcano}

[4] The present eruption of SHV, Montserrat, began in 1995 and has been characterised by the repetitive growth and collapse of a series of andesitic lava domes [e.g., Watts et al., 2002]. In 1997, during periods of rapid magma extrusion $\left(>5 \mathrm{~m}^{3} \mathrm{~s}^{-1}\right.$ [Sparks et al., 1998]) intermittent cyclic behaviour was observed on both seismic and deformation records [Voight et al., 1998]. The cycles exhibit periods ranging between $\sim 8$ and 22 hours and occurred during periods of dome instability. The deformation was recorded as tilt, $\theta$, defined as the change in angle that the edifice slope makes with respect to the horizontal, i.e., for the radial tilt component,

$$
\theta_{r}=\tan ^{-1}\left(-\frac{\partial}{\partial r} U_{z}\right),
$$

where $r$ is the horizontal direction pointing away from the active lava dome and $U_{z}$ is the vertical ground displacement. A positive tilt reflects the steepening of the edifice slope.

[5] The characteristics of the deformation field become apparent when the tilt caused by the inflation of a strain nucleus within an elastic halfspace [Mogi, 1958] is considered. The tilt can be expressed as,

$$
\theta_{r}=\frac{9 a^{3} \Delta P}{4 \mu} \frac{r z}{\left(r^{2}+z^{2}\right)^{5 / 2}},
$$

where $r$ and $z$ are the horizontal and vertical distances between recording site and pressure source (nucleus of strain) respectively, and $a$ is the source radius. $\Delta P$ is the overpressure, and $\mu$ is the shear modulus of the halfspace. Equation (2) indicates that the amplitude of the tilt is dependent on the source strength $\left(\Delta P a^{3}\right)$ whereas the tilt wavelength is a function of the source location $(r$ and $z$ ).

[6] In May 1997, during a period of cyclic activity, two tiltmeters, CP2 and CP3, were simultaneously operational at distances of $\sim 770 \mathrm{~m}$ and $\sim 630 \mathrm{~m}$ from the active vent respectively (Figure 1). These two tilt records have been used to estimate both the dimensions and boundary stress conditions of the deformation source [e.g., Voight et al., 1999; Cayol, 2003; Widiwijayanti et al., 2005]. The previous models, which all assume an isotropically pressurised deformation source, indicate that the top of the pressurised region must be in the top $1000 \mathrm{~m}$ of the conduit. However, the large source strengths predicted by these models are difficult to reconcile with geological parameters. At SHV the conduit diameter is inferred to be $\sim 30 \mathrm{~m}$ [Voight et al., 1999; Melnik and Sparks, 2002] and the tensile strength of the edifice at shallow depths is estimated at $<10 \mathrm{MPa}$ [Sparks, 1997]. Yet the isotropic pressurisation models 


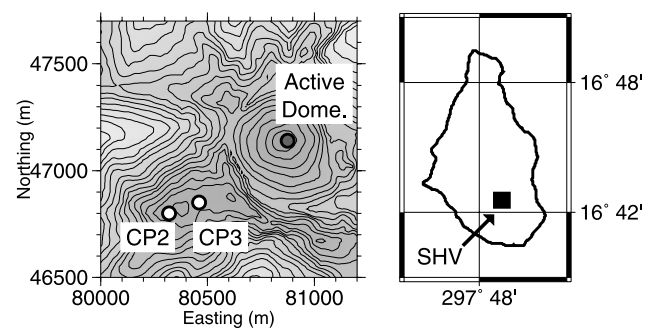

Figure 1. The position of the two tiltmeters located close to the dome at Soufrière Hills volcano (SHV), Montserrat [after Voight et al., 1998]. CP3 is $\sim 630 \mathrm{~m}$ and CP2 is $\sim 770 \mathrm{~m}$ from the active vent. Contours increment at $50 \mathrm{~m}$ intervals, with both tiltmeters located at $\sim 890 \mathrm{~m}$ a.s.1. The area covered by the map is shown as a black square on the outline of Montserrat to the right.

suggest that the pressure source at SHV requires a radius of $>200 \mathrm{~m}$ to ensure the corresponding overpressure would not cause explosive edifice failure. Widiwijayanti et al. [2005] suggested that a fractured, water-saturated region surrounding the conduit may form this extended pressurised zone.

\section{Methodology}

[7] Numerical models of the deformation field at SHV were constructed using the Boundary Element Model (BEM) of Cayol and Cornet [1997]. Realistic topography is incorporated into this model as pronounced relief can alter the morphology and magnitude of surface deformation at steep-sided volcanoes [Cayol and Cornet, 1998].

[8] Three types of models were constructed:

[9] 1. Analytical solutions for a pressurised cylindrical conduit buried within a halfspace, following Voight et al. [1999]. This allows for comparison with previous work.

[10] 2. A pressurised conduit within a volcanic edifice with realistic topography (using the BEM). This model represents an inflation of the conduit due to overpressurised magma displacing the conduit walls (Figure 2a). Cayol et al. [2004] considered such deformation sources beneath realistic topography. We extend this work by modelling the tilt

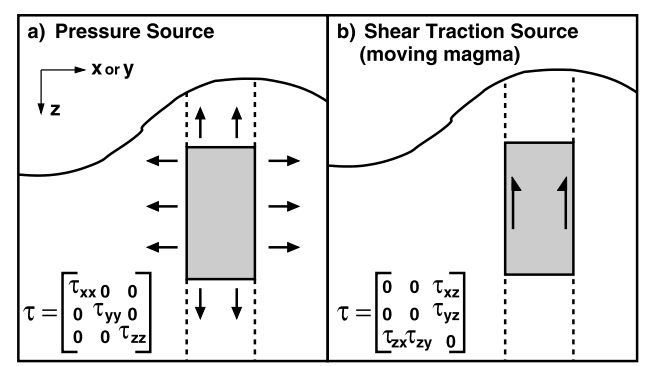

Figure 2. The two styles of deformation considered in this paper. (a) An isotropic pressurised conduit section representing an inflation of the conduit and (b) a shear traction model used to represent shear stresses at the wall of the conduit section, associated with vertical pressure gradients along the conduit. The stress tensor for each source is given at the bottom left of the panels. associated with a range of conduit depths and lengths, determining the range of conduit geometries compatible with the measured tilt.

[11] 3. A conduit with a vertical traction boundary condition, within an edifice with realistic topography. This model simulates deformation due to only the shear stress exerted by the viscous magma on the conduit walls (Figure 2b). Such shear stresses are a consequence of magma flow due to a pressure gradient along the conduit.

[12] The conduit was assumed to be a vertical cylinder with a radius of $15 \mathrm{~m}$, located directly below the active dome at SHV. A Young's Modulus, E, of 2 GPa was taken for the edifice, consistent with estimates used by Voight et al. [1999] and Widiwijayanti et al. [2005].

[13] The modelled displacements allowed tilt to be calculated at the location of both instruments, CP2 and CP3, for a range of conduit lengths and burial depths. The tilt ratio, $\theta_{\mathrm{CP} 3} / \theta_{\mathrm{CP} 2}$, is a useful analysis parameter because, for elastic deformation models, it is primarily a function of source/instrument separation (see equation (2)). Therefore, as the lateral position of the conduit is assumed, tilt ratios provide an estimate of the source depth. Furthermore, as linear elasticity is assumed, the amplitude of the modelled tilt scales linearly with source strength, allowing the stress magnitude which generates the measured tilt at SHV to be estimated. To ensure that the measurements reflect only the cyclic tilt variations, the tilt ratio is calculated from amplitude differences between successive tilt minima, $\theta^{\mathrm{min}}$, and maxima, $\theta^{\max }$, at both stations,

$$
\frac{\theta_{\mathrm{CP} 3}}{\theta_{\mathrm{CP} 2}}=\frac{\left(\theta^{\max }-\theta^{\min }\right)_{\mathrm{CP} 3}}{\left(\theta^{\max }-\theta^{\min }\right)_{\mathrm{CP} 2}} .
$$

\section{Results}

[14] The set of 14 tilt ratios for the period between $23 \mathrm{rd}$ and 30th May 1997 have a mean value of 1.28 (in agreement with Voight et al. [1999]) and a median value of 1.19 (Figure 3). The mean tilt cycle amplitude at CP3, used for calculations of absolute pressure and traction values, is $17.5 \mu \mathrm{rad}$.

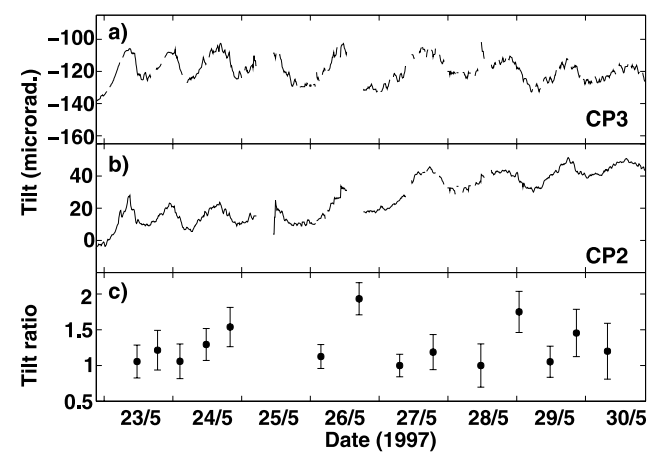

Figure 3. Radial tilt records for stations (a) CP3 and (b) CP2 for May 23rd to 30th 1997, the only period that the two stations are recording simultaneously. (c) The tilt ratios, $\theta_{C P 3} / \theta_{C P 2}$. The error bars reflect the uncertainty in maxima/ minima measurements due to noise inherent on the records. Data gaps are due to loss of signal transmission from the instruments. 

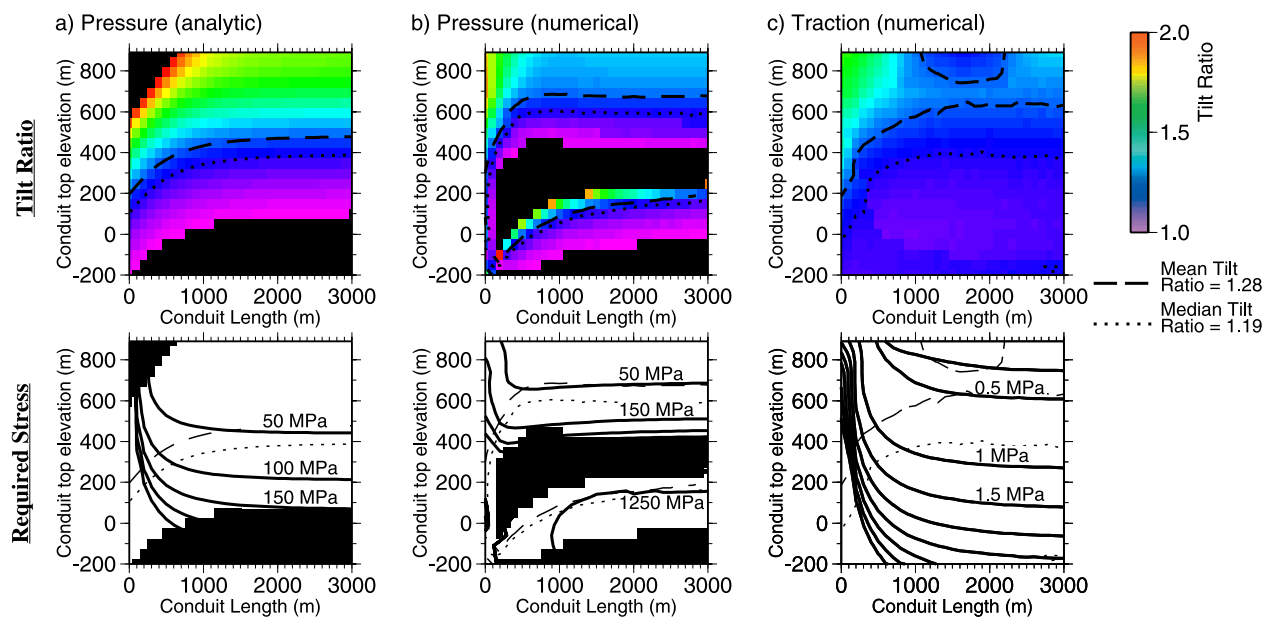

Figure 4. The variation of both (top) tilt ratio, $\theta_{C P 3} / \theta_{C P 2}$, (colour shades) and the (bottom) stress required to match the observed tilt amplitude, $\theta_{C P 3}=17.5 \mu$ rad (labelled solid contours) over realistic ranges of source elevation (m above sea level) and conduit length. Three models are tested: (a) the analytic halfspace solution for a cylindrical conduit, and numerical solutions for a cylindrical conduit with both (b) pressure boundary conditions and (c) vertical traction boundary conditions beneath realistic topography. The broken line contours indicate the conduit parameters which produce tilts matching the data values. Shaded areas indicate regions where $1>\theta_{C P 3} / \theta_{C P 2}>2$. In the centre of Figures $4 \mathrm{~b}$ (top) and $4 \mathrm{~b}$ (bottom) the tilt ratio passes through a discontinuity as the direction of tilt switches at the stations. All conduits have a radius of $15 \mathrm{~m}$, and the edifice deformation modulus is held at $2 \mathrm{GPa}$.

[15] The results of modelling the tilt ratios for a range of conduit lengths and burial depths are given in Figure 4. The analytical halfspace models (Figure 4a) restate the results of Voight et al. [1999] for comparison. The conduits which fit best with the mean tilt ratio, given a length $>1000 \mathrm{~m}$, have their tops at elevations between 400 and $500 \mathrm{~m}$ above sea level (a.s.l.). If the median tilt ratio is taken, the maximum elevation is lowered to between 250 and $350 \mathrm{~m}$ (a.s.1.). The lower panel of Figure 4a shows that overpressures of 40 to $80 \mathrm{MPa}$ are required to generate tilt amplitudes of $17.5 \mu \mathrm{rad}$ at station CP3. Solutions for shorter conduits are possible at deeper burial depths and with greater overpressures.

[16] For numerical models with realistic topography and an isotropic pressure source (Figure $4 b$ ) the conduits which best fit the data, while requiring the lowest overpressures, are located with their tops at elevations of between 600 and $700 \mathrm{~m}$ a.s.l. (considering both mean and median tilt ratio values). These conduits are longer than $700 \mathrm{~m}$, and the range of possible pressures remain high at 50 to $100 \mathrm{MPa}$. Solutions for shorter conduit again require much greater overpressures. The topography constrains the conduit top to shallow burial depths, above $400 \mathrm{~m}$ a.s.l., as sources whose top surface is below $400 \mathrm{~m}$ a.s.l. exhibit a switch in the polarity of the tilt ratio. Cayol and Cornet [1998] observed this feature for models with steep topography where tilt polarity in the summit area can become reversed.

[17] When applying a vertical traction along the conduit boundary (Figure $4 \mathrm{c}$ ) the tilt ratio is less sensitive to changes in conduit length and location in comparison to isotropic pressure sources. However, the same conduits fit the data best: long conduits $(\geq 1000 \mathrm{~m})$ reaching shallow depths (400-600 $\mathrm{m}$ a.s.l.). However, absolute traction values required to match tilt amplitudes lie within a narrow range of between 0.5 and $1.5 \mathrm{MPa}$.

[18] The changes in tilt ratio with varying conduit elevation and conduit length show similar characteristics for all three models (Figure 4). The morphology of this modelspace implies that the tilt is sensitive to the elevation of the conduit top as shown by Cayol et al. [2004] but insensitive to conduit length for lengths larger than $500 \mathrm{~m}$. Therefore, shallow processes dominate the recordings. For the vertical shear source models this implies that the reaction force at the base of the ascending magma column, estimated at SHV to be at depths of $\sim 5 \mathrm{~km}$ [Aspinall et al., 1998; Barclay et al., 1998], has a negligible effect on surface tilt.

\section{Discussion}

[19] The results confirm that, as reported previously in the literature, the deformation measured by tilt is associated with a source that reaches shallow levels, i.e., located within the upper few hundred metres of the edifice. As tilt measurements are insensitive to deep sources the vertical extent of the deformation source is unconstrained (Figure 4), hence a 'shallow source' in this context means a pressure source reaching shallow depths. The addition of realistic topography, with an isotropically pressurised source model, does not alter the results significantly. Both models of isotropically pressurised conduits with $r=15 \mathrm{~m}$ require a shallow overpressure of greater than $40 \mathrm{MPa}$. This is much greater than the tensile strength of the surrounding edifice, which is estimated to be $<10 \mathrm{MPa}$ [Sparks, 1997]. Previous models [e.g., Widiwijayanti et al., 2005; Cayol, 2003] invoked sources with much larger radii to compensate for the overpressure required.

[20] The most interesting result is that using shear traction of the conduit wall as a deformation source at SHV can reproduce the measured tilt ratios (Figure 4c). However, the model is only physically plausible if the observed tilt amplitudes can be generated by realistic magma conduit pressure gradients and the associated shear stresses. Sparks 
[1997] shows that large pressure gradients develop in the upper few hundred metres of andesitic magma conduits due to the combined effects of increased viscosity and microlite crystallisation; both effects resist magma flow, allowing pressure to build at depth.

[21] Physically attainable shear stresses along a conduit wall can be estimated by assuming the stresses are set up by laminar steady-state flow through a circular tube. In this case the vertical shear stress at the wall of the tube, $\tau_{r z}$, is given by [e.g., Bird et al., 2002, p. 50]:

$$
\tau_{r z}=\frac{r}{2} \frac{\mathrm{dP}}{\mathrm{dz}}
$$

where $r$ is the radius of the conduit and $\mathrm{d} P / \mathrm{d} z$ is the vertical pressure gradient in excess of the magmastatic pressure. Therefore, to achieve a shear stress of $0.5 \mathrm{MPa}$, which can explain the observed tilt amplitudes (Figure 4c), an excess pressure gradient of $\sim 6.7 \times 10^{4} \mathrm{~Pa} \mathrm{~m}^{-1}$ is required along a conduit of $30 \mathrm{~m}$ diameter. The Newtonian flow models of Sparks [1997] suggest that excess pressure gradients of up to $3.5 \times 10^{4} \mathrm{~Pa} \mathrm{~m}^{-1}$ are achievable across the top $1000 \mathrm{~m}$ of an andesitic conduit, dependent on the average viscosity along the magma column and the excess magma chamber pressure. Such a pressure gradient would generate shear stresses of $0.26 \mathrm{MPa}$. For simplicity these models do not take into account the overpressure associated with the shear traction. However, further modelling shows such an overpressure would have a small effect, accounting for $<20 \%$ of the tilt amplitude.

[22] These results suggest that shear stresses along the conduit wall should be considered as a plausible deformation model within the upper $1000 \mathrm{~m}$ of the edifice. The pressure gradients estimated from the flow models of Sparks [1997] are still a factor of 2 smaller than those required to explain the tilt amplitude by shear stresses alone. However, the model is physically more plausible than a highly overpressurised (60 MPa) conduit section [Voight et al., 1999] and does not require a source of radius $>200 \mathrm{~m}$ [Widiwijayanti et al., 2005]. The discrepancy between the shear stresses required to generate the tilt (Figure 4c) and those from flow models may be associated with uncertainties in the edifice rigidity estimate, the geometry of the magma conduit, or the modelled magma rheology. Indeed, if a Young's modulus of $1 \mathrm{GPa}$ was taken, as by Widiwijayanti et al. [2005], then the modelled and observed tilt amplitudes would match.

[23] Further constraint for the physical processes causing the deformation cycles is provided by the simultaneously occurring seismicity. Green and Neuberg [2006] show that this low-frequency seismicity is associated with relaxation of the volcanic edifice. Combined with the evidence that low-frequency earthquakes at SHV are generated at depths $>1000 \mathrm{~m}$ below the surface [Rowe et al., 2004; Neuberg et al., 2006] it is hard to reconcile such seismicity with a shallow pressurisation: how could shallow relaxation be causally linked to deeper seismicity? It has been suggested that low-frequency seismicity is triggered by the brittle failure of melt when strain-rates in the magma flow are high [e.g., Goto, 1999; Neuberg et al., 2006]. This provides a link between seismicity and our proposal that deformation may be linked to conduit wall shear stresses. Future work will include a joint interpretation of the deformation and seismicity to constrain the magma flow regime.

\section{Conclusions}

[24] Tilt recorded at SHV during periods of rapid magma extrusion is indicative of changes in stress within the upper $1000 \mathrm{~m}$ of the magmatic system. We have shown that shear stress at the conduit wall must be considered as a deformation source alongside the more popular isotropic pressure sources. Shear stresses, of approximately the correct magnitude to generate the observed tilt at $\mathrm{SHV}$, are produced by realistic pressure gradients $\left(3.5 \times 10^{4} \mathrm{~Pa} \mathrm{~m}^{-1}\right)$ along a conduit of $15 \mathrm{~m}$ radius. The shear stress models have advantages over the pressurisation models in that they do not require conduits of unrealistically large radius or physically implausible overpressures in order to explain the observed tilt amplitude.

[25] Acknowledgments. This work was funded by NERC through $\mathrm{Ph} . \mathrm{D}$. grant NER/S/A/2002/10478 and by the European Commission project, MULTIMO (contract EVG1-CT-2000-00021). The authors thank Steve Sparks and Greg Houseman for insightful discussions. Two anonymous reviewers provided comments which greatly improved this manuscript.

\section{References}

Aspinall, W., A. Miller, L. Lynch, J. Latchman, R. Stewart, R. White, and J. Power (1998), Soufrière Hills eruption, Montserrat, 1995-1997: Volcanic earthquake locations and fault plane solutions, Geophys. Res. Lett., $25,3397-3400$

Barclay, J., M. Rutherford, M. Carroll, M. D. Murphy, J. D. Devine, J. Gardner, and R. S. J. Sparks (1998), Experimental phase equilibria constraints on pre-eruptive storage conditions of the Soufrière Hills magma, Geophys. Res. Lett., 25, 3437-3440.

Beauducel, F., F.-H. Cornet, E. Suhanto, T. Duquesnoy, and M. Kasser (2000), Constraints on magma flux from displacements data at Merapi volcano, Java, Indonesia, J. Geophys. Res., 105, 8192-8203.

Bird, R. B., W. E. Stewart, and E. N. Lightfoot (2002), Transport Phenomena, 2nd ed., 895 pp., John Wiley, Hoboken, N. J.

Cayol, V. (2003), Anelastic deformation on Montserrat, Eos Trans. AGU, 84(46), Fall Meet. Suppl., Abstract V52E-03.

Cayol, V., and F. H. Cornet (1997), 3D mixed boundary elements for elastostatic deformation field analysis, Int. J. Rock Mech. Min. Sci., 34, $275-287$.

Cayol, V., and F. H. Cornet (1998), Effect of topography on the interpretation of the deformation field of prominent volcanoes: Application to Etna, Geophys. Res. Lett., 25, 1979-1982.

Cayol, V., D. N. Green, and J. Neuberg (2004), Location of the source of deformations and hybrid earthquake cycles at Montserrat, paper presented at IAVCEI General Assembly, Pucon, Chile.

Dvorak, J. J., and D. Dzurisin (1997), Volcano geodesy: The search for magma reservoirs and the formation of eruptive vents, Rev. Geophys., 35, $343-384$

Goto, A. (1999), A new model for volcanic earthquakes at Unzen volcano: Melt rupture model, Geophys. Res. Lett., 26, 2541-2544.

Green, D. N., and J. Neuberg (2006), Waveform classification of lowfrequency earthquake swarms and its implication at Soufrière Hills volcano, Montserrat, J. Volcanol. Geotherm. Res., 153(1-2), doi:10.1016/ j.jvolgeores.2005.08.003

Melnik, O., and R. Sparks (2002), Dynamics of magma ascent and lava extrusion at Soufrière Hills volcano, Montserrat, in The Eruption of Soufrière Hills Volcano, Montserrat, From 1995 to 1999, edited by T. H. Druitt and B. P. Kokelaar, Geol. Soc. Mem., 21, 153-171.

Mogi, K. (1958), Relations between the eruptions of various volcanoes and the deformations of the ground surface around them, Bull. Earthquake Res. Inst. Univ. Tokyo, 36, 99-134.

Neuberg, J., H. Tuffen, L. Collier, D. N. Green, T. Powell, and D. B. Dingwell (2006), The trigger mechanism of low-frequency earthquakes on Montserrat, J. Volcanol. Geotherm. Res., 153(1-2), doi:10.1016/j. jvolgeores.2005.08.008

Rowe, C. A., C. H. Thurber, and R. A. White (2004), Dome growth behaviour at Soufrière Hills volcano, Montserrat, revealed by relocation of 
volcanic event swarms, 1995-1996, J. Volcanol. Geotherm. Res., 134, $199-221$.

Sparks, R. S. J. (1997), Causes and consquences of pressurisation in lava dome eruptions, Earth Planet. Sci. Lett., 150, 177-189.

Sparks, R. S. J., et al. (1998), Magma production and growth of the lava dome of the Soufrière Hills volcano, Montserrat, West Indies: November 1995 to December 1997, Geophys. Res. Lett., 25, 3421-3424.

Voight, B., R. P. Hoblitt, A. B. Clarke, A. B. Lockhart, A. D. Miller, L. Lynch, and J. McMahon (1998), Remarkable cyclic ground defomation monitored in real-time on Montserrat, and its use in eruption forecasting, Geophys. Res. Lett., 25, 3405-3408.

Voight, B., et al. (1999), Magma flow instability and cyclic activity at Soufrière Hills volcano, Montserrat, British West Indies, Science, 283 , $1138-1142$.
Watts, R. B., R. A. Herd, R. S. J. Sparks, and S. R. Young (2002), Growth patterns and emplacement of the andesitic lava dome at Soufrière Hills volcano, Montserrat, in The Eruption of Soufrière Hills Volcano, Montserrat, From 1995 to 1999, edited by T. H. Druitt and B. P. Kokelaar, Geol. Soc. Mem., 21, 115-152.

Widiwijayanti, C., A. Clarke, D. Elsworth, and B. Voight (2005), Geodetic constraints on the shallow magma system at Soufrière Hills volcano, Montserrat, Geophys. Res. Lett., 32, L11309, doi:10.1029/ 2005GL022846.

V. Cayol, Laboratoire Magmas et Volcans, Université Blaise Pascal, F-63038 Clermont-Ferrand, France.

D. N. Green and J. Neuberg, School of Earth and Environment, University of Leeds, Leeds LS2 9JT, UK. (david.n.green@googlemail.com) 